\title{
A BIBLIOTECA DA CATEQUISTA: VESTÍGIOS DA CIRCULAÇÃO INTERNACIONAL DE MODELOS PEDAGÓGICOS NAS LEITURAS PRESCRITAS PARA AS PROFESSORAS CATÓLICAS ${ }^{1}$
}

\author{
Evelyn de Almeida Orlando ${ }^{2}$
}

\section{RESUMO}

Este artigo discute a renovação educacional católica no Brasil, a partir das prescrições de leituras feitas para as professoras primárias em consonância com as discussões pedagógicas modernas no cenário nacional e internacional, publicadas no Boletim Catequético. O objetivo é analisar como os papéis da catequista e da professora primária se misturam quando a catequese passa pelo processo de escolarização. Além disso, busca analisar a presença de autores estrangeiros nas leituras prescritas às professoras, dando a ver como a Igreja Católica foi produzindo também seus modelos culturais e renovando suas práticas educativas, buscando situar-se nas demandas do seu tempo social.Situado no âmbito da História Cultural, o aporte teórico deste trabalho passa pelos conceitos de campo religioso (BOURDIEU, 2005), representações, práticas e apropriações (CERTEAU, 1994, CHARTIER, 1990), circulação de modelos pedagógicos (CARVALHO, 1994, 2006). A análise das prescrições de leituras para as professoras/catequistas serve como pistas da presença da Igreja nesse movimento de circulação internacional de modelos pedagógicos, considerando a liberdade relativa dos agentes na diversidade dos usos desses modelos, em suas práticas de apropriação e na forma como estas incidem diretamente na construção do mundo social.

Palavras-chave: Formação de professores; Circulação de saberes pedagógicos; Pedagogia católica moderna.

\section{THE “BIBLIOTECA DA CATEQUISTA” (CATECHIST'S LIBRARY): TRACES OF INTERNATIONAL CIRCULATION OF PEDAGOGICAL MODELS IN THE SUGGESTED READINGS FOR CATHOLIC TEACHERS}

\begin{abstract}
This article discusses the Catholic educational renewal in Brazil, from the suggested readings for primary teachers in line with modern pedagogical discussions at the national and international scene, published in "Boletim Catequético". The objective is to analyze how the role sof catechist and school teacher are mixed when catechesis goes through the schooling process. It also seeks to analyze the presence of foreign authors in readings indicated for teachers, showing how Catholic Church was also producing its cultural models and renewing their educational practices, seeking to be in consonance with the demands of its social time. Situated within the Cultural History, the theoretical contribution of this work goes through the concepts of religious field (BOURDIEU, 2005), representations, practices and appropriations (CERTEAU, 1994; CHARTIER, 1990), circulation of pedagogical models (CARVALHO, 1994, 2006). The analysis of suggested readings for teachers/catechists works as clues to the presence of the Church in this movement of international circulation of pedagogical models, considering the relative freedom of the agents in the diversity of uses of these models, in their practices of appropriation and in how these practices directly affect the construction of the social world.
\end{abstract}

Keywords: School teacher formation, Pedagogical Knowledge circulation, Modern Catholic Pedagogy 


\section{Introdução}

Este artigo discute a renovação educacional católica no Brasil, a partir das prescrições de leituras feitas para as professoras primárias em consonância com as discussões pedagógicas modernas no cenário nacional e internacional, publicadas no Boletim Catequético $^{3}$. Busca-se compreender como a Igreja Católica participou do movimento de circulação de modelos pedagógicos que contribuiu para reconfigurar o campo educacional de diferentes países, dentre eles o Brasil, desde o final do século XIX, com ênfase nas primeiras décadas do século XX.

Nesse movimento ancorado nos enunciados da Pedagogia Moderna e, posteriormente, das Escolas Novas, a escola é alçada a um lugar privilegiado que a transforma em agência legítima para promover a educação. As práticas ali desenvolvidas ganhavam o selo da legitimidade por estarem assentadas nas contribuições das Ciências da Educação, traduzindo dessa forma a sua relação direta com o cientificismo dos novos tempos.

A educação passou, aos poucos, a ser confundida com a escolarização, e seus processos vão organizando em torno de si um conjunto de saberes, valores, comportamentos que passam a ser assumidos como marcas de uma identidade. Todas as formas e saberes que configuram os processos de escolarização podem ser entendidas como produtos de uma construção cultural diretamente associados a questões sociais e demandas sociais dos diferentes tempos e espaços onde a escola vai sendo organizada e configurada como símbolo do nova educação, moderna e civilizada.

Esse destaque para a escolarização assume um lugar importante também nos discursos católicos, ainda que sob outro enfoque. Sem retirar a primazia das famílias na tarefa de educar seus filhos, a Igreja Católica vai, paulatinamente, aderindo ao discurso da importância da escola como instrumento de disputa pelo campo educacional. A catequese passa por um processo de escolarização, não porque os educadores católicos reconheçam a escola como lugar privilegiado para a educação, mas porque ali os professores têm mais tempo e oportunidades de ministrar o ensino religioso, a doutrina e a moral católicas associadas a contextos mais próximos da vida do aluno. Tal estratégia dá à catequese escolar o tom de uma doutrina viva e, pedagogicamente, os métodos de ensino utilizados passam a ser considerados modernos uma vez que são os mesmos daqueles utilizados nas outras disciplinas escolares.

A escolarização da catequese não é um caminho novo para a Igreja que surge no século XIX ou XX. Ela está posta como possibilidade para um repensar da catequese desde o século XVIII, como uma consequência da mentalidade iluminista. Escola para todos, reforma escolar e instrução religiosa serviram como tripé para o iluminismo católico alemão, o qual privilegia a educação moral. Assim,

À reforma escolar de Vitório Amadeu II, na Sabóia em 1729, segue-se a de Frederico II, na Prussia em 1763-65, e de Maria Teres na Áustria em 1774. Estes últimos apoiam-se na obra de Johan Ignaz Von Felbiger (1724-88), abade dos cônegos regrantes de S. Agostinho de Sagan, na Silésia, desde 1758. Preocupado pelo fato de as escolas católicas serem tão retrógradas em comparação com as protestantes, apoiado pelo seu amigo o prior Benedikt Staruch (1724-1803), realiza a reforma escolar em Sagan, tirando proveito da organização didática e dos métodos aprendidos na "Realshule berlinense, dirigida por J.J. Hecker, que tinha ido visitar pessoalmente (BOLLIN \& GASPARIN, 1998, p. 155) ${ }^{4}$. 
No final do século XIX e início do XX, reacende um antigo caminho que a Igreja já havia sinalizado para a catequese: sua apropriação no âmbito escolar. Uma vez escolarizada, os saberes por ela empreendidos se pulveriza nos processos de escolarização da sociedade. Nos diferentes modos e processos pelos quais a cultura escolar vai marcando a sociedade brasileira, ditando seus tempos e hábitos, conformando um tipo de cidadão mais apropriado para o mundo do trabalho e devidamente moralizado, há uma impregnação de valores, hábitos e comportamentos próprios de uma cultura católica.

Dessa forma, quando a catequese passa pelo processo de escolarização, os papéis da catequista e da professora primária se misturam e a formação doutrinária vem acompanhada da formação pedagógica em suas bases mais modernas. A presença de autores estrangeiros nas leituras prescritas às professoras dá a ver os modos pelos quais a Igreja Católica foi produzindo também seus modelos culturais e renovando suas práticas educativas, buscando situar-se nas demandas do seu tempo social.

Entender esse processo sob a ótica da História Cultural significa compreender a produção, a circulação e a apropriação de saberes pedagógicos como construções culturais em sua dimensão social. A renovação educacional que marca o campo religioso católico é entendida como uma estratégia de se manter em condições de disputa pelo campo educacional, afirmando-se sobre as escolas protestantes e laicas. Há, portanto, uma tensão estabelecida entre campo religioso e campo educacional que marca as estratégias da Igreja católica nesse momento ${ }^{5}$.

O diálogo e as apropriações dos modelos pedagógicos em voga no século $\mathrm{XX}$ coincidem com as novas orientações do papado para o a educação católica. Nesse século, um intenso movimento de renovação pôs em crise uma formulação catequética, cristalizada no interior da Igreja há alguns séculos, motivada por alguns fatores: os estudos teológicos, as orientações do pensamento, o contexto sócio-cultural e as novas instâncias pedagógicas. (BOLLIN \& GASPARINI, 1998, p.208). A este trabalho interessa, sobretudo, este último fator.

Nesse contexto, a análise das prescrições de leituras para as professoras/catequistas serve como pistas da presença da Igreja nesse movimento de circulação internacional de modelos pedagógicos, considerando a liberdade relativa dos agentes na diversidade dos usos desses modelos, em suas práticas de apropriação e na forma como estas incidem diretamente na construção do mundo social.

\section{A professora católica, uma catequista por excelência}

Depois de um período de descristianização que se instaura a partir de meados do século XVIII, surgem novas tentativas de fazer a catequese responder aos problemas sociais que lhe abrem outras dimensões: a dimensão bíblica, a antropológica e a escolar. (BOLLIN \& GASPARIN, 1998, p. 158).

As novas instâncias pedagógicas que surgem acabam por influenciar a catequese em suas bases pedagógicas, sobretudo. A Pedagogia do catecismo passou a ser profundamente influenciada pela Pedagogia Moderna e pelas novas orientações psicopedagógicas das ciências da educação. Com isso, modificou a sua práxis metodológica, abandonando a metodologia pós-tridentina. Influenciada, inicialmente, pelo método indutivo, também conhecido como Método de Munique ${ }^{6}$, a partir de 1920, a Pedagogia do catecismo estreitou o diálogo com as concepções das Escolas Novas.

Do conjunto de acontecimentos que marcaram a história do movimento catequético, no século $\mathrm{XX}$, dois merecem destaque: os documentos pontifícios que foram escritos para 
normatizar e impulsionar o catecismo e os congressos que serviram como espaço de fomento às discussões acerca das ciências educacionais, que resultaram em novos investimentos na área.

Dos documentos pontifícios, deve-se considerar, obrigatoriamente, pela sua importância, a Encíclica Acerbo Nimis (1905), de Pio X, única encíclica destinada ao catecismo e a Encíclica Divini Illius Magistri (1929), do Papa Pio XI, sobre educação cristã da juventude.

Para Bollin e Gasparini, o século XX é o século dos Congressos e Encontros Catequísticos que tiveram o mérito de alargar o debate sobre a catequese, envolvendo um número maior de pessoas. Dentre os principais, podem-se destacar o Congresso de Milão, em 1909; os congressos de Viena realizados em 1905, 1912, 1925; os Congressos de Munique, realizados em 1905, 1911, 1912, 1928; em Paris, nos anos de 1908, 1912, 1934, 1939, 1955, 1957, 1960; na Espanha, em Valladolid, em 1913, em Granada, em 1926; em Zaragoza, em 1930 e em Valência, em 1950. Nesse mesmo ano, em Roma, foi realizado o I Congresso Catequístico Internacional, com 600 participantes representando 37 Institutos Religiosos e quase 350 dioceses (BOLLIN e GASPARINI, 1998, p. 216). Neste último, Álvaro Negromonte participou representando Brasil.

Os congressos, assim como os centros, institutos e revistas catequéticas, funcionavam como espaços de sociabilidade, que serviam para disseminar o pensamento católico, assim como davam visibilidade aos sujeitos que circulavam nesses espaços imprimindo neles a sua marca.

No Brasil, o Boletim Catequético, principal fonte deste trabalho, constitui-se nesse espaço das revistas catequéticas. Produzido em 1936, na cidade de Belo Horizonte, como uma iniciativa do Departamento Arquidiocesano de Ensino Religioso após o $1^{\circ}$ Congresso Católico de Educação, tinha como objetivo contribuir com a formação das catequistas, preparando-as para sua atuação no espaço escolar.

Paralelamente, publicações do tipo dos Boletins foram emergindo no cenário nacional, sinalizando para um movimento de renovação educacional que se alastrava pelo campo religioso. $\mathrm{O}$ frei Oscar Lustosa, importante historiador da Igreja, aponta a existência em vários estados de iniciativas congêneres, todas voltadas para a melhor preparação dos professores como catequistas. Tinham como características comuns serem "pequenos, locais ou quando muito regionais, como o Boletim Catequético de Belo Horizonte, MG. Boletim da cruzada de educadoras católicas de Recife, PE. A Folha Catequética de Porto Alegre, RS" (LUSTOSA, 1992, p. 127). Em geral, os boletins possuem um espectro mais restrito do ponto de vista do conteúdo veiculado, se comparados às revistas, por exemplo. Estas, geralmente, têm uma circulação maior e visam propagar suas ideias em um âmbito mais vasto. No entanto, seu editor, o padre Álvaro Negromonte, tratava o BoletimCatequético, em sua própria ficha técnica, como uma revista catequética mensal, e é dessa forma que ele sempre o referenciava. Esse é um elemento significativo que permite pensar na aspiração do padre de fazer seu projeto alçar vôos mais altos, e sinaliza para o sentido formativo e não apenas informativo - mais comum nesse tipo de publicação - que o impresso realmente possuía junto ao professorado.

Associar a formação da professora à da catequista e incitar essa ação conjunta nas salas de aula das escolas primárias do estado de Minas Gerais significava instituir, de forma legítima, uma cultura católica com o aval do próprio estado, tendo em vista que essas ações foram pensadas para os professores das escolas públicas e privadas. Significava, ainda, promover a formação de um perfil de professora que deveria ter a consciência integral dos seus deveres sociais e cristãos, mobilizando-se em prol do projeto de recristianização da nação. 
Nesse sentido, além do tipo de professor que se pretendia formar, o Boletim Catequético veiculava ainda um modelo de pedagogia católica que aliava elementos da pedagogia moderna, entendida como arte de ensinar, com alguns dos enunciados das escolas novas. Incorporados ao catolicismo, os princípios da Pedagogia Moderna, que serviram para modelar a escola paulista do final do século XIX, dividem o cenário educacional com muitos enunciados escolanovistas. Os enunciados e as prescrições veiculadas no Boletim Catequético dão mostras de como essa renovação do campo educacional católico estava impregnada de "modos de fazer" tão marcados pela Pedagogia Moderna do início do século.

Essa preocupação em dialogar com as correntes escolanovistas, sem relegar os professores às suas próprias interpretações das novas orientações, levou muitos intelectuais católicos a se mostrarem abertos às novas correntes, naquilo que não ferisse os princípios católicos, mantendo a prática de mostrar aos professores "modos de fazer" essa incorporação em suas salas de aula. Apesar dos novos cânones, as lições práticas permaneceram como dispositivos fundamentais do projeto pedagógico de formação de professores católicos.

O processo de produção do Boletim levou em consideração uma representação de professora como agente responsável pela inculcação dos valores e hábitos católicos nos futuros cidadãos. Tal "missão", entretanto, demandava um perfil considerado como apropriado, não só para o exercício da tarefa educativa, mas para a posição de visibilidade que essas mulheres passavam a ocupar, sob o aval da Igreja. O engajamento das mulheres na obra social e educativa da Igreja serviu para que houvesse uma revisão das características consideradas tipicamente femininas. Atributos como a passividade, outrora considerados quase como inerentes às mulheres, não cabiam mais em um contexto onde essas mesmas mulheres começavam a brigar e ganhar, aos poucos e com grande custo, alguns espaços na sociedade.

Usar essa disposição para a militância em favor das ações educativas foi uma das estratégias adotadas pela Igreja para fabricar professoras/catequistas. Com isso, ampliavase a esfera de ação da mulher burguesa, aumentava-se seu poder de expressão e de visibilidade, tornando-a partícipe de um projeto maior político e social em defesa dos interesses do catolicismo. Esse outro lugar, no entanto, circunscrevia-anum padrão de moralidade e comportamento que tinha na visibilidade tão desejada a sua maior censora.

O perfil da professora catequista, inscrito reiteradas vezes e de tantas formas no Boletim Catequético, subtendia um modelo de mulher católica que deveria ser forte, resoluta, consciente da sua missão educativa e, consequentemente, da sua importância para o futuro do país. Apesar de toda essa exposição funcionar como um freio regulador, muitas mulheres corroboraram com essas normatizações, contribuindo com a sua propagação, como forma de satisfazer aspirações pessoais. As normas funcionavam para censurar, ao mesmo tempo em que serviam para promover um tipo de comportamento exemplar, carregado de um sentido de distinção social. Dentro dessas prescrições, a "boa catequista" deveria possuir sólida formação intelectual, pedagógica, doutrinária e moral, que compreendia, dentre outras coisas, saber bem o catecismo, preparar bem as aulas, usar bons métodos em suas salas de aula, realizar a meditação de manhã, nunca descuidar do exame de consciência, cuidar da leitura espiritual, ir à missa e à comunhão todos os dias. Além disso, deveria deixar sobressair o seu maior dom: amar as crianças. Assim, sua vida e seus valores poderiam servir como um espelho aos seus alunos e à sociedade. Em diferentes números, esses atributos eram ressaltados, ou em página cheia, ou em pequenos quadros que funcionavam para chamar a atenção do leitor, ocupando uma parte significativa da página. Nesse panorama, o número 35, publicado em agosto de 1939, traz 
um desses quadros que se destaca, nesse universo, pela forma como se intitula: alguns traços para o retrato da educadora perfeita, um fragmento traduzido do livro Comment former des hommes, de Henry Pradel. Assim, ele define:

Alguns traços para o retrato da educadora perfeita:

- Não digamos que não há nada a fazer com tais alunos.

- Não nos iludamos sobre nossa aparente autoridade.

- Não tomemos o lugar da criança, paralisando-lhe as iniciativas.

- $\quad$ Não poupemos esforços.

- Não imponhamos, mas façamos desejar o que queremos.

- Não sejamos excessivamente administrativas.

- $\quad$ Não desprezemos as tarefas modestas.

- $\quad$ Não sejamos meticulosas demais.

- Não condenemos todos os alunos a dar o mesmo resultado.

- $\quad$ Não deixemos os alunos mais inteligentes submetidos ao regime comum. (PRADEL, 1939, p. 12)

É interessante perceber como as próprias mulheres assumiram esse papel de difundir essa representação e essa função pedagógica e moral que lhes foram sendo atribuídas, desempenhando entre o público feminino um papel de censoras, antes atribuído quase que exclusivamente à Igreja.

A epígrafe de Pio XI, utilizada na capa do $n^{\circ}$ 51, atribuía às mulheres grande parte da responsabilidade da educação e propagação da religião católica. "O fruto do catecismo depende quase totalmente do zelo, da inteligência e da habilidade com que as catequistas conseguirem tornar o ensino mais fácil e agradável" (Boletim Catequético, 1941, capa). Na última página, uma mulher, Judith Monteiro, demonstrava não só ter assimilado a mensagem, como incitava outras mulheres na mesma direção, referindo-se da seguinte maneira às catequistas:

Já pensaste alguma vez que muitas e muitas das crianças que te foram confiadas, não terão oportunidade de receber outro ensino de catecismo, outra formação da alma, a não ser a que lhe deres? [...] De teu esforço depende, pois a salvação de muitas almas... Este pensamento não te dá coragem para o trabalho catequista? (MONTEIRO, 1941, p. 13)

De uma maneira geral, o Boletim tinha um caráter, sobretudo, formativo, mas funcionando também como um importante veículo de informação acerca do que estava sendo produzido na área, desde as mais recentes e recomendadas publicações, aos eventos realizados que abordassem a temática do ensino religioso. Com isso, seu diretor se propunha a atualizar o professor em relação às novidades pedagógicas e às ações da Igreja no campo educacional, assim como às iniciativas congêneres de outros países. 


\section{A Biblioteca da Catequista}

A Biblioteca da Catequista era uma das seções do Boletim Catequético. A forma de organização e a ordem dada a essa biblioteca seguem a seguinte lógica: alguns títulos apareceram listados na própria seção. No entanto, como esta seção não se manteve com esse título em todos os números do Boletim, optei por manter a ideia apresentada pelo periódico de formar uma biblioteca para as catequistas, incorporando à lista de livros organizada também os livros apresentados sob o rótulo "Livros para as catequistas" e outras sugestões de leitura que, frequentemente, de forma solta, apareciam no Boletim. Muitos desses livros foram indicados várias vezes, como os do abade Quinet, de Marie Fargues, de Waleska Paixão e do próprio padre Álvaro Negromonte.

As leituras prescritas nessas seções permitem averiguar o enfoque dado ao conhecimento religioso na formação dessas professoras e das crianças. $\mathrm{O}$ aspecto pedagógico era abordado, frequentemente, no âmbito do "saber fazer", através da divulgação de obras de autores estrangeiros que vinham incorporando as contribuições das ciências da educação em suas aulas de ensino religioso, servindo como modelos para as professoras brasileiras.

Dessa forma a Biblioteca se organiza conforme quadro abaixo:

Quadro: Biblioteca da catequista

\begin{tabular}{|c|c|c|c|}
\hline Título & Autor & Referência & Comentários \\
\hline $\begin{array}{l}\text { O catecismo segundo o } \\
\text { Evangelho }\end{array}$ & Charles & \multirow[t]{2}{*}{$\begin{array}{l}\text { BC, Ano I, , no } \\
1, \text { abril, 1936, p. } \\
4\end{array}$} & Sem referência \\
\hline $\begin{array}{l}\text { Lições catequéticas para } \\
\text { os pequeninos }\end{array}$ & Quinet & & Excelentes para os dois primeiros anos \\
\hline Catecismo Explicado & Mons. Cauly & \multirow[t]{4}{*}{$\begin{array}{l}\text { BC, Ano I, } \mathrm{n}^{\circ} \\
3, \text { junho, } 1936 \text {, } \\
\text { p. } 9\end{array}$} & \multirow[t]{4}{*}{$\begin{array}{l}\text { A redação envia estes livros e quais quer } \\
\text { outros se os pedidos vierem } \\
\text { acompanhados do valor e o porte do } \\
\text { correio. }\end{array}$} \\
\hline Bíblia das Escolas & Ecker & & \\
\hline $\begin{array}{l}\text { Philote’a ou Introdução } \\
\text { à vida devota }\end{array}$ & $\begin{array}{l}\text { São Francisco de } \\
\text { Salles }\end{array}$ & & \\
\hline $\begin{array}{l}\text { A vida espiritual } \\
\text { reduzida a três } \\
\text { princípios }\end{array}$ & Pe. Mesckler & & \\
\hline $\begin{array}{l}\text { A formação da } \\
\text { consciência }\end{array}$ & Waleska Paixão & \multirow[t]{7}{*}{$\begin{array}{l}\text { BC, Ano I, , no } \\
4, \text { julho, } 1936 \\
\text { p. } 5,7\end{array}$} & \\
\hline $\begin{array}{l}\text { O catecismo official }\left(1^{\circ},\right. \\
\left.2^{\circ} \text { e } 3^{\circ}\right)\end{array}$ & & & \\
\hline O Novo Testamento & Pe. Rhoden & & \\
\hline Bíblia das Escolas & Ecker & & \\
\hline Catecismo Explicado & Mons. Cauly & & \\
\hline $\begin{array}{l}\text { Lições catequéticas para } \\
\text { os pequeninos }\end{array}$ & Quinet & & \\
\hline $\begin{array}{l}\text { Introdução à vida } \\
\text { devota }\end{array}$ & $\begin{array}{l}\text { S. Francisco de } \\
\text { Salles }\end{array}$ & & \\
\hline
\end{tabular}




\begin{tabular}{|c|c|c|c|}
\hline $\begin{array}{l}\text { A vida espiritual } \\
\text { reduzida a três } \\
\text { princípios }\end{array}$ & P. Meschler & & \\
\hline Horas Cathequéticas & Schreiner & & \\
\hline O méthodo Eucarístico & P. Poppe & & \\
\hline Jeux de Catéchisme & C. Bruel & $\begin{array}{l}\text { BC, Ano I, , } \mathrm{n}^{\circ} \\
\text { 5-6, ago-set, } \\
\text { 1936, p. } 14\end{array}$ & \\
\hline Pedagogia Catechistica & Llorente & $\begin{array}{l}\text { BC, Ano I, } \mathrm{n}^{\circ} 7, \\
\text { outubro, 1936, } \\
\text { p. } 07\end{array}$ & $\begin{array}{l}\text { Todos esses fazem parte da Seção } \\
\text { Pedagógica da II Exposição Catequética, } \\
\text { publicados em uma página cheia do } \\
\text { Boletim. }\end{array}$ \\
\hline $\begin{array}{l}\text { Pèdagogie Du } \\
\text { Catechisme }\end{array}$ & Quinet & & \\
\hline O Método Eucarístico & P. Poppe & & \\
\hline $\begin{array}{l}\text { Prècis de pedagogie } \\
\text { catechistique }\end{array}$ & Henri Martin & & \\
\hline $\begin{array}{l}\text { Lezione populare di } \\
\text { pedagogia catechetica }\end{array}$ & Luigi Vigna & & \\
\hline Catequesis Biblicas & D. Llorente & & \\
\hline $\begin{array}{l}\text { Tratado Elemental de } \\
\text { pedagogia catequística }\end{array}$ & D. Llorente & & \\
\hline $\begin{array}{l}\text { Catecismo explicado } \\
\text { com gráficos y } \\
\text { exemplos }\end{array}$ & D. Llorente & & \\
\hline $\begin{array}{l}\text { Lecciones de História } \\
\text { Eclesiástica }\end{array}$ & D. Llorente & & \\
\hline $\begin{array}{l}\text { Catequeses sobre a } \\
\text { confissão e a comunhão } \\
\text { das crianças }\end{array}$ & Henrique Stieglitz & & \\
\hline Lições Catequéticas & Abbè Quinet & & \\
\hline $\begin{array}{l}\text { Cadernos catequéticos - } \\
\text { vol. } 1 \text { - métodos e } \\
\text { programas }\end{array}$ & Waleska Paixão & & \\
\hline $\begin{array}{l}\text { O Catecismo pelo } \\
\text { Evangelho }\end{array}$ & P. Charles & & \\
\hline Horas Catequéticas & Schreiner & & \\
\hline $\begin{array}{l}\text { Apontamentos do } \\
\text { catequista }\end{array}$ & Quinet & & \\
\hline La voie spirituelle & Wothe Bolton & & \\
\hline Educador apóstolo & Guibert & & \\
\hline
\end{tabular}




\begin{tabular}{|c|c|c|c|}
\hline Il vangelo nella scuola & $\begin{array}{l}\text { Michele } \\
\text { Pellegrino }\end{array}$ & & \\
\hline $\begin{array}{l}\text { La formation religieuse } \\
\text { dês enfants du peupel }\end{array}$ & Marie Fargues & & \\
\hline $\begin{array}{l}\text { Comment j'enseigne La } \\
\text { masse a mes tout petits }\end{array}$ & $\begin{array}{l}\text { Religiosa } \\
\text { Benedictina }\end{array}$ & & \\
\hline $\begin{array}{l}\text { Comment j'enseigne } \\
\text { l'Année liturgique a } \\
\text { mes petits }\end{array}$ & $\begin{array}{l}\text { Religiosa } \\
\text { Benedictina }\end{array}$ & & \\
\hline Pontos de religião & $\begin{array}{l}\text { Fr. F. de P. } \\
\text { Capuchinho }\end{array}$ & & \\
\hline $\begin{array}{l}\text { Formation Chrétienne } \\
\text { de "Mes tout Petits" }\end{array}$ & M. M. d'Aubigny & & \\
\hline $\begin{array}{l}\text { Explicação do pequeno } \\
\text { catecismo }\end{array}$ & Slater & & \\
\hline $\begin{array}{l}\text { Meus cadernos de } \\
\text { instrução religiosa }\end{array}$ & Quinet & & \\
\hline $\begin{array}{l}\text { Instructions pour lês } \\
\text { cathechismes de } \\
\text { perseverance }\end{array}$ & Ch. Beaussart & & \\
\hline $\begin{array}{l}\text { Explication dialogada } \\
\text { del catecismo }\end{array}$ & D. Llorente & & \\
\hline $\begin{array}{l}\text { Explication dialogada } \\
\text { del Evangelio }\end{array}$ & D. Llorente & & \\
\hline $\begin{array}{l}\text { Puntos de catecismo (3 } \\
\text { vol.) }\end{array}$ & Padre Vilarinho & & \\
\hline Manual do catequista & M. S. C. & & \\
\hline La mére éducatrice & Abbè Simon & & \\
\hline $\begin{array}{l}\text { La pesonalité de } \\
\text { l'enfant }\end{array}$ & J. Burret & & \\
\hline Catecismo da educação & René Bethleem & & \\
\hline $\begin{array}{l}\text { Cadernos Catequéticos: } \\
\text { formação da } \\
\text { consciência }\end{array}$ & Waleska Paixão & $\begin{array}{l}\text { BC, Ano I, } \mathrm{n}^{\circ} 8, \\
\text { novembro, } \\
1936, \text { p. } 16\end{array}$ & $\begin{array}{l}\text { Neste número são anunciados dois livros } \\
\text { a serem lançados pela professora Maria } \\
\text { Luiza Cunha, um para as crianças e outro } \\
\text { para as professoras. Três páginas são } \\
\text { destinadas à publicação de duas } \\
\text { primeiras lições como uma pequena } \\
\text { amostra para os leitores. }\end{array}$ \\
\hline O caminho da Vida & P. A. Negromonte & $\begin{array}{l}\text { BC, Ano II, } n^{\circ} \\
\text { 13, junho, } 1937, \\
\text { verso de capa }\end{array}$ & $\begin{array}{l}\text { Indicado como o mais completo tratado } \\
\text { de moral escrito em português. } \\
\text { Indispensável às catequistas e } \\
\text { professoras. }\end{array}$ \\
\hline $\begin{array}{l}\text { Pedagogia do } \\
\text { Catecismo }\end{array}$ & P. A. Negromonte & $\begin{array}{l}\text { BC, Ano II, } \mathrm{n}^{\circ} \\
17 \text {, outubro, } \\
1937, \text { p. } 16\end{array}$ & $\begin{array}{l}\text { Indicado como a primeira obra do gênero } \\
\text { em língua portuguesa para catequistas, } \\
\text { escolas Normais, Colégios Católicos e o } \\
\text { reverendíssimo clero. }\end{array}$ \\
\hline Nos resplendores da & Pe. Augusto & BC, Ano II, $\mathrm{n}^{\circ}$ & \\
\hline
\end{tabular}




\begin{tabular}{|c|c|c|c|}
\hline hóstia & Magne & $\begin{array}{l}17, \quad \text { outubro, } \\
1937, \text { p. } 22\end{array}$ & \\
\hline $\begin{array}{l}\text { Cruzada Eucarística } \\
\text { Infantil }\end{array}$ & $\begin{array}{l}\text { Coleção Fides } \\
\text { Intrepida (12 } \\
\text { folhetos) }\end{array}$ & & \\
\hline $\begin{array}{l}\text { La croizade } \\
\text { Eucharisque }\end{array}$ & Marie Fargues & & \\
\hline Manual de Religião & P. A. Negromonte & $\begin{array}{l}\text { BC, Ano III, no } \\
\text { 19, fevereiro, } \\
\text { 1938, p. } 13 \\
\text { BC, Ano III, no } \\
\text { 19, fevereiro, } \\
\text { 1938, } \\
\text { contracapa } \\
\text { Lista publicada } \\
\text { também no } \\
\text { BC, Ano III, no } \\
\text { 20, março, } \\
\text { 1938, } \\
\text { contracapa. }\end{array}$ & $\begin{array}{l}\text { Propaganda do livro Manual de Religião, } \\
\text { em página cheia com transcrição da } \\
\text { opinião do pe. Hélder Câmara, } \\
\text { manifestada em correspondência ao } \\
\text { autor. } \\
\text { Com exceção do manual de Religião, } \\
\text { todos os demais livros foram publicados } \\
\text { na contracapa dos Boletins no } 19 \text { e } 20 \text {. } \\
\text { sob o título "livros para o Ensino } \\
\text { Religioso" }\end{array}$ \\
\hline $\begin{array}{l}\text { Apontamentos do } \\
\text { Catequista (3 vol) }\end{array}$ & Quinet & & \\
\hline Métodos e Programas & Waleska Paixão & & \\
\hline $\begin{array}{l}\text { Formação da } \\
\text { consciência }\end{array}$ & Waleska Paixão & & \\
\hline $\begin{array}{l}\text { Apelo de Cristo aos } \\
\text { pescadores de almas } \\
\text { Catequeses }\end{array}$ & Henrique Stieglitz & & \\
\hline O caminho da vida & P.A. Negromonte & & \\
\hline $\begin{array}{l}\text { O catecismo segundo o } \\
\text { Evangelho: o livro dos } \\
\text { pequenos; o livros das } \\
\text { mães e catequistas; o } \\
\text { livro dos sacerdotes }\end{array}$ & $\begin{array}{l}\text { Abbè Eug. } \\
\text { Charles }\end{array}$ & & \\
\hline O catequista prático & $\begin{array}{l}\text { Por um amigo da } \\
\text { infância }\end{array}$ & & \\
\hline Esboços catequéticos & $\begin{array}{l}\text { Henrique } \\
\text { Stieglitz, trad. } \\
\text { Milton Luiz } \\
\text { Valente }\end{array}$ & & \\
\hline $\begin{array}{l}\text { Explicação do pequeno } \\
\text { catecismo }\end{array}$ & Pe. Jacob Slater & & \\
\hline Horas catequéticas & Georg Schreiner & & \\
\hline
\end{tabular}




\begin{tabular}{|c|c|c|c|}
\hline Lições catequéticas para & Quinet & & \\
\hline $\begin{array}{l}\text { Quadros bíblicos do } \\
\text { antigo e Novo e } \\
\text { testamento (Série de } 40 \\
\text { quadros) }\end{array}$ & $\begin{array}{l}\text { Editora Herder \& } \\
\text { Cia }\end{array}$ & & \\
\hline $\begin{array}{l}\text { Para os pequenos no } \\
\text { Jardim de Infância }\end{array}$ & Quinet & & \\
\hline Espírito do Cura d'Ars & Abbè A. Monnin & & \\
\hline $\begin{array}{l}\text { Resumo da História } \\
\text { Sagrada }\end{array}$ & F. B. H. & & \\
\hline História Sagrada & F.B.H. & & \\
\hline $\begin{array}{l}\text { Cantae, criancinhas: } \\
\text { catecismo popular em } \\
\text { verso e música }\end{array}$ & $\begin{array}{l}\text { Por um } \\
\text { franciscano }\end{array}$ & & \\
\hline $\begin{array}{l}\text { Meu caderno de } \\
\text { instrução religiosa }\end{array}$ & $\begin{array}{l}\text { Segundo o método } \\
\text { Quinet e adaptado } \\
\text { às obras do } \\
\text { mesmo autor }\end{array}$ & & \\
\hline A Bíblia das escolas & Thiago Ecker & & \\
\hline $\begin{array}{l}\text { A Pedagogia do } \\
\text { catecismo }\end{array}$ & P. A. Negromonte & $\begin{array}{l}\text { BC, Ano III, } \text { n }^{\circ} \\
21 \text {,abril, 1938, } \\
\text { p. verso de capa } \\
\text { BC, Ano III, no } \\
\text { 21, abril, 1938, } \\
\text { p. } 6 \\
\text { idem }\end{array}$ & $\begin{array}{l}\text { Opinião do pe. Guilherme Boing } \\
\text { publicada em página cheia do Boletim. } \\
\text { "Conhecendo a literatura francesa, alemã, } \\
\text { holandesa, etc, neste particular, ouso } \\
\text { dizer que pe. Álvaro Negromonte pode } \\
\text { colocar galhardamente seu livro ao lado } \\
\text { das publicações estrangeiras". }\end{array}$ \\
\hline $\begin{array}{l}\text { Para os pequeninos do } \\
\text { Jardim de infância }\end{array}$ & Quinet & & \\
\hline Lições Catequéticas & Quinet & & \\
\hline $\begin{array}{l}\text { A Pedagogia do } \\
\text { catecismo }\end{array}$ & P. A. Negromonte & $\begin{array}{l}\text { BC, Ano III, } \mathrm{n}^{\circ} \\
22, \text { maio, 1938, } \\
\text { verso de capa } \\
\text { Lista publicada } \\
\text { na contracapa } \\
\text { idêntica aos } \\
\text { números } 19 \text { e } \\
20 \\
\text { BC, Ano III, no } \\
22, \text { maio, } 1938 \text {, } \\
\text { p. } 13\end{array}$ & $\begin{array}{l}\text { Mais uma vez, o Boletim destina uma } \\
\text { página inteira para propaganda de um } \\
\text { livro do seu diretor, com a opinião do pe. } \\
\text { Guilherme Boing. Dessa vê, sobre o } \\
\text { recém-lançado "Manual de Religião", } \\
\text { transcrita do jornal O Diário. }\end{array}$ \\
\hline $\begin{array}{l}\text { O catecismo segundo o } \\
\text { evangelho }\end{array}$ & $\begin{array}{l}\text { P. Eugenio } \\
\text { Charles }\end{array}$ & & \\
\hline
\end{tabular}




\begin{tabular}{|c|c|c|c|}
\hline Horas Catequéticas & Schreiner & & \\
\hline Manual de Religião & P. A. Negromonte & & \\
\hline $\begin{array}{l}\text { Pedagogia do } \\
\text { Catecismo }\end{array}$ & P.A. Negromonte & \multirow{5}{*}{$\begin{array}{l}\text { BC, Ano III, } \mathrm{n}^{\circ} \\
22 \text {, maio, } 1938, \\
\text { verso de capa } \\
\text { Idem } \\
\text { BC, Ano III, } \mathrm{n}^{\circ} \\
22 \text {, maio, } 1938 \text {, } \\
\text { p. } 6 \\
\text { idem }\end{array}$} & \multirow[t]{5}{*}{$\begin{array}{l}\text { Lista de livros para o ensino religioso } \\
\text { publicada na contracapa }\end{array}$} \\
\hline & & & \\
\hline Manual de Religião & P.A. Negromonte & & \\
\hline $\begin{array}{l}\text { Apontamentos do } \\
\text { Catequista }\end{array}$ & Quinet & & \\
\hline Catecismo dos meninos & Melle. Hemptinne & & \\
\hline $\begin{array}{l}\text { A Pedagogia do } \\
\text { Catecismo } \\
\text { Manual de Religião }\end{array}$ & $\begin{array}{l}\text { P. A. Negromonte } \\
\text { P.A. Negromonte }\end{array}$ & $\begin{array}{l}\text { BC, Ano III, } \mathrm{n}^{\circ} \\
23, \text { junho, 1938, } \\
\text { p. } 3,4\end{array}$ & $\begin{array}{l}\text { Lista de livros para o ensino religioso } \\
\text { publicada na contracapa }\end{array}$ \\
\hline $\begin{array}{l}\text { A Igreja } \\
\text { Jesus Cristo }\end{array}$ & $\begin{array}{l}\text { J. P. Junglas } \\
\text { Karl Adam }\end{array}$ & $\begin{array}{l}\text { BC, Ano III, } n^{\circ} \\
24, \text { julho, } 1938, \\
\text { p. } 3,4\end{array}$ & \\
\hline $\begin{array}{l}\text { Pedagogia do } \\
\text { Catecismo }\end{array}$ & P. A. Negromonte & $\begin{array}{l}\text { BC, Ano III, } \mathrm{n}^{\circ} \\
25, \quad \text { agosto, } \\
1938, \text { verso de } \\
\text { capa }\end{array}$ & \\
\hline Manual de Religião & P. A. Negromonte & & \\
\hline Diretrizes Catequéticas & P. A. Negromonte & $\begin{array}{l}\text { BC, Ano III, }{ }^{\circ} \\
27, \text { outubro, } \\
1938 \text {, verso de } \\
\text { capa }\end{array}$ & \\
\hline Diretrizes Catequéticas & P.A. Negromonte & $\begin{array}{l}\text { BC, Ano III, } \mathrm{n}^{\circ} \\
28, \text { novembro, } \\
1938 \text {, p. verso } \\
\text { da contracapa }\end{array}$ & \\
\hline Diretrizes catequéticas & P. A. Negromonte & $\begin{array}{l}\text { BC, Ano III, } n^{\circ} \\
29 \text {, novembro, } \\
1939 \text {, verso de } \\
\text { capa }\end{array}$ & \\
\hline Diretrizes catequéticas & P. A. Negromonte & $\begin{array}{l}\text { BC, Ano IV, } \mathrm{n}^{\circ} \\
30, \quad \text { março, } \\
1939 \text {, verso da } \\
\text { contracapa }\end{array}$ & \\
\hline $\begin{array}{l}\text { Plano de lições de } \\
\text { Catecismo para o I e II } \\
\text { anos nos grupos } \\
\text { escolares }\end{array}$ & $\begin{array}{l}\text { Evangelina } \\
\text { Gonzaga e Julieta } \\
\text { Magalhães }\end{array}$ & $\begin{array}{l}\text { BC, Ano IV, } \mathrm{n}^{\circ} \\
34 \text {, julho, } 1939 \text {, } \\
\text { p. } 4\end{array}$ & $\begin{array}{l}\text { Com parecer da prof. Waleska Paixão em } \\
\text { duas páginas. }\end{array}$ \\
\hline $\begin{array}{l}\text { Méthode Pédagogique } \\
\text { de l'ensignement Du } \\
\text { Catéquisme }\end{array}$ & Abbé C. E. Roy & $\begin{array}{l}\text { BC, Ano IV, } n^{\circ} \\
34, \text { julho, } 1939, \\
\text { p. } 11\end{array}$ & $\begin{array}{l}\text { Com Apreciação de uma página cheia de } \\
\text { Waleska Paixão. }\end{array}$ \\
\hline A Doutrina Viva & P. A. Negromonte & $\mathrm{BC}$, Ano IV, $\mathrm{n}^{\circ}$ & \\
\hline
\end{tabular}




\begin{tabular}{|c|c|c|c|}
\hline & & $\begin{array}{l}35, \text { agosto, } \\
1939, \text { verso de } \\
\text { capa }\end{array}$ & \\
\hline $\begin{array}{l}\text { Manual de Religião ( } 2^{a} \\
\text { edição) }\end{array}$ & P. A. Negromonte & & \\
\hline A doutrina Viva & P. A. Negromonte & $\begin{array}{l}\text { BC, Ano IV, } \text { n }^{\circ} \\
36 \text {, setembro, } \\
1939 \text {, verso de } \\
\text { capa }\end{array}$ & \\
\hline $\begin{array}{l}\text { Pedagogia Catequética: } \\
\text { Apontamentos }\end{array}$ & F. F. Capuchinho & $\begin{array}{l}\text { BC, Ano IV, } n^{\circ} \\
38 \text {, novembro, } \\
1939 \text {, p. } 9\end{array}$ & \\
\hline $\begin{array}{l}\text { Pedagogia do } \\
\text { Catecismo }\end{array}$ & P. A. Negromonte & $\begin{array}{l}\text { BC, Ano IV, }{ }^{\circ} \\
38 \text {, novembro, } \\
1939 \text {, verso da } \\
\text { contracapa }\end{array}$ & \\
\hline O Caminho da Vida & P. A. Negromonte & & \\
\hline Doutrina Viva & P. A. Negromonte & & \\
\hline $\begin{array}{l}\text { Apontamentos do } \\
\text { catequista (3 vols) }\end{array}$ & Quinet & & \\
\hline $\begin{array}{l}\text { Lições catequéticas para } \\
\text { os pequeninos }\end{array}$ & Quinet & & \\
\hline $\begin{array}{l}\text { Para os pequeninos no } \\
\text { Jardim de infância }\end{array}$ & Quinet & & \\
\hline $\begin{array}{l}\text { Apelo de Jesus aos } \\
\text { pescadores de almas }\end{array}$ & Quinet & & \\
\hline $\begin{array}{l}\text { O catecismo pelo } \\
\text { Evangelho (livro do } \\
\text { catequista) }\end{array}$ & Charles & & \\
\hline Catecismo dos meninos & Hemptinne & & \\
\hline Planos de aula & $\begin{array}{l}\text { Evangelina } \\
\text { Gonzaga e Julieta } \\
\text { Lopes }\end{array}$ & & \\
\hline Bíblia das escolas & Excker & & \\
\hline As fontes do Salvador & P. A. Negromonte & $\begin{array}{l}\text { BC, Ano VI, } \mathrm{n}^{\circ} \\
49 \text {, abril, 1941, } \\
\text { contracapa }\end{array}$ & $\begin{array}{l}\text { Anúncio de todos os livros de texto do } \\
\text { pe. A. Negromonte destinados ao curso } \\
\text { secundário. }\end{array}$ \\
\hline As Fontes do Salvador & $\begin{array}{l}\text { P. A. } \\
\text { Negromonteq }\end{array}$ & $\begin{array}{l}\text { BC, Ano VI, } \mathrm{n}^{\circ} \\
\text { 50, maio, 1941, } \\
\text { contracapa }\end{array}$ & \\
\hline Os Santos Evangelhos & $\begin{array}{l}\text { P. A. Negromonte } \\
\text { (tradução e } \\
\text { anotações) }\end{array}$ & $\begin{array}{l}\text { BC, Ano VI, } n^{\circ} \\
51 \text {, junho, } 1941, \\
\text { p. contracapa }\end{array}$ & \\
\hline $\begin{array}{l}\text { Cadernos de Religião } \\
\text { (desenho para colorir) }\end{array}$ & $\begin{array}{l}\text { Sem indicação de } \\
\text { autoria }\end{array}$ & $\begin{array}{l}\text { BC, Ano VI, } \mathrm{n}^{\circ} \\
\text { 52, julho, 1941, } \\
\text { contracapa }\end{array}$ & $\begin{array}{l}\text { Exemplar destinado ao } 1^{\circ} \text { ano primário. } \\
\text { Nota informativa sobre a preparação dos } \\
\text { outros cadernos para as séries seguintes. }\end{array}$ \\
\hline
\end{tabular}




\begin{tabular}{|c|c|c|}
\hline $\begin{array}{l}\text { Nos resplendores da } \\
\text { hóstia }\end{array}$ & $\begin{array}{l}\text { Pe. Augusto } \\
\text { Magne }\end{array}$ & $\begin{array}{l}\text { BC, Ano VI, }{ }^{\circ} \\
52 \text {, julho, 1941, } \\
\text { p. } 7\end{array}$ \\
\hline $\begin{array}{l}\text { Cruzada Eucarística } \\
\text { Infantil }\end{array}$ & $\begin{array}{l}\text { Coleção "Fides } \\
\text { Intrepida" (12 } \\
\text { folhetos) }\end{array}$ & \\
\hline $\begin{array}{l}\text { La Croisada } \\
\text { Eucharistique }\end{array}$ & Marie Fargues & \\
\hline $\begin{array}{l}\text { Prie! Communie! } \\
\text { Sacrifiic-ti! Sois } \\
\text { Apôtre! Les vocances } \\
\text { Du croisé. L'heure } \\
\text { d'adoration Du croisé }\end{array}$ & Por Fidelis & \\
\hline
\end{tabular}

Fonte: Organizado pela autora com base no Boletim Catequético (1936-1941).

Ancorado na crítica feita à falta de material didático produzido no âmbito nacional, no primeiro ano do Boletim as prescrições de leitura são, de forma predominante, de textos de autores estrangeiros. Grande parte dos livros recomendados fazia parte da produção francesa ou belga e os autores mais referenciados eram o abade Quinet ${ }^{7}$ e Marie Fargues ${ }^{8}$, os quais já vinham aplicando os métodos ativos e as contribuições da psicologia no ensino religioso. Tais autores reaparecem ao longo das demais edições, tanto nas recomendações de leituras, quanto em excertos distribuídos ao longo do Boletim e na Seção Página do Mestre, traduzidos.

A partir do segundo ano, nota-se um aumento significativo na divulgação de literatura religiosa nacional. O próprio editor do Boletim investe fortemente nesse campo e seus livros figuram como leituras quase obrigatórias para as catequistas, chegando mesmo a serem utilizados como referência para o currículo do ensino religioso pelo padre Hélder Câmara. O Boletim também é utilizado como espaço de divulgação das obras de seus principais colaboradores, como a professora Waleska Paixão e Evangelina Gonzaga. Waleska Paixão não só publica livros nacionais como traduz alguns dos autores franceses recomendados. Essa mudança significativa na indicação de livros nacionais significava uma articulação entre os modelos pedagógicos e culturais em circulação no cenário internacional com a realidade brasileira.

A circulação de modelos internacionais no Boletim pode ser percebida em três instâncias: as recomendações dos autores em seus originais, as traduções e as produções nacionais inspiradas nessas obras. Desse modo, é possível perceber que diferentes estratégias foram utilizadas na produção de uma pedagogia moderna no Boletim Catequético. Prática semelhante acontecia em outros impressos, como a Revista do Ensino, por exemplo. De acordo com Bicas (2006) a linha editorial da revista foi produzida ao mesmo tempo em que a produziu,

[...] a partir de concepções pedagógicas fundamentadas na arte de ensinar, mescladas à introdução das novas correntes pedagógicas que estavam sendo trabalhadas na França, Inglaterra, Dinamarca e Suiça para as quais a criança era considerada um ser ativo (2006, p. 99). 
A França, sobretudo, foi o grande polo inspirador para o diretor do periódico. Nas raras vezes em que ele citou iniciativas congêneres à do Boletim, referiu-se à revista Catéchistes, publicada na França pelo grupo lassalista e apresentado como um grande veículo de formação de catequistas naquele país. Não foi possível identificar se Negromonte foi leitor assíduo dessa publicação ${ }^{9}$, mas é possível inferir algumas estratégias semelhantes daquela revista na fórmula editorial do periódico, como o uso de artigos produzidos por personalidades notórias, dentre as quais se incluíam numerosos expoentes do movimento catequético internacional, como Quinet, Fargues, Boyer, os quais foram traduzidos inúmeras vezes no BoletimCatequético. Esses sujeitos tiveram uma larga importância nesse movimento de renovação catequética em âmbito internacional. Em Portugal, seus nomes também são indicados nessa direção. De acordo com D. Cristino,

Estes autores, para além de serem os mais próximos e conhecidos,
influenciaram largamente a catequese em Portugal. O movimento
catequístico protagonizado na acção e nas obras destes pedagogos e
catequetas insere-se na grande renovação que atravessou a Igreja desde
meados do séc. XIX e levou ao Concílio Vaticano II, especialmente
através da influência dos movimentos bíblico, litúrgico, tomista e, mais
tarde, o do apostolado organizado dos leigos. (1994, p. 130)

Os temas que vinham alimentando os debates pedagógicos daqueles tempos foram enfocados, ressaltando e afirmando a posição da Igreja em relação, sobretudo, às questões educacionais: finalidade da educação, moral e dogma, catequese e valores terrenos, liberdade religiosa, pessoa humana foram assuntos abordados, muitas vezes. Outros autores aparecem de forma recorrente como excertos do Boletim, mas curiosamente seus livros não figuram na Biblioteca da Catequista, talvez pelo fato de suas obras estarem mais relacionadas à questões teóricas, sendo pouco práticos. Assim, seus textos figuram apenas na Página dos Mestres ou como pequenas chancelas de autoridade ao longo do periódico. Dentre esses autores, destaco Dechamps ${ }^{10}$ e De Hovre ${ }^{11}$. Ambos faziam parte da direção da Coleção Les sciences et l'Art de l'Éducation ${ }^{12}$.A ausência de seus textos na Biblioteca da Catequista reforça o caráter instrumental do Boletim.

Esta é uma característica que marca os livros prescritos nessa Seção. Todos os livros indicados são livros, potencialmente, de uso escolar ${ }^{13}$. Não sendo necessariamente didáticos, eles se afiguram como tal pelas possibilidades de uso em sala de aula ou como leitura complementar do ensino religioso. Mesmo os textos mais doutrinários, como os do padre Negromonte, são livros destinados ao ensino secundário. Tais indicações, além de se constituírem uma leitura de fácil assimilação pelos professores, reforçava o processo de escolarização da catequese ao pedagogizar textos doutrinários e inseri-los no universo escolar. Pensar esse movimento no interior do campo religioso implica entender que há uma tendência, entre os especialistas do campo religioso, de se fecharem na referência autárquica do saber religioso, já acumulado, e de concentrar grande parte da produção, inicialmente, para os próprios produtores. A autonomia do campo, inclusive, afirma-se nessa tendência. Entretanto, "o campo religioso distingue-se do campo intelectual propriamente dito, pois nunca consegue dedicar-se total e exclusivamente a uma produção esotérica, isto é, destinada apenas aos produtores, devendo sempre sacrificar-se às exigências dos leigos" (BOURDIEU, 2005, p. 38).

Pensar nos usos que são feitos dessas prescrições remete a pensar que existe uma distância entre os usos prescritos e efetivos tal como assinala Chartier (1990). Em uma das seções do Boletim, chamada Consultas, é possível apreenderindícios desses usos. Ao devolverem suas experiências ao Boletim, por meio de questões de naturezas distintas, 
alguns professores davam a ver modos de fazer da prática docente, vestígios de usos efetivos ${ }^{14}$ das lições prescritas que permitem ao historiador investigar um recorte da educação de difícil apreensão que é o das apropriações. Estas, neste caso, fornecem indícios da autonomia do professorado em relação ao que lhe foi prescrito, dando a ver o que foi apreendido dessas prescrições em suas práticas. $\mathrm{O}$ que foi feito desses saberes e como eles foram reelaborados, reconstituídos, organizados e sistematizados se converte em uma experiência que incide na própria produção e constituição do campo dos saberes pedagógicos e revela como a produção de um campo é sempre alimentada por tensões e relações de força que se estabelecem em uma disputa, nem sempre explícita, por um lugar de poder nesse próprio campo, traduzidas nas táticas de apropriação, tal como assinalam Certeau (1994) e Chartier (1990).

Por se dirigirem às professoras, em sua maioria formadas, as prescrições de leituras não passam por textos pedagógicos ou de autores das Ciências da Educação, mas de autores católicos que já usaram se apropriaram desses enunciados em suas propostas e textos doutrinários. Supondo que a parte pedagógica já havia sido suprida pela Escola Normal, essa seção parece ter como objetivo munir as professoras catequistas de conhecimento acerca da doutrina católica, de livros que mostram como se apropriar da pedagogia nova no ensino religioso, materiais pedagógicos produzidos nessa concepção.

A estratégia de se produzir uma Biblioteca Pedagógica voltada para a formação docente vinha sendo utilizada por diferentes grupos de educadores no Brasil. Conforme Vidal (2001), a constituição de uma Biblioteca pedagógica revela um investimento no desenvolvimento pessoal, profissional e o desejo de atualização, que sinaliza para o universo cultural e pedagógico em que se movem os seus leitores.

De acordo com Toledo (2001), a partir dos anos de 1920, as coleções pedagógicas se difundiram no Brasil com um sentido político de intervenção no campo pedagógico. No âmbito do catolicismo, intelectuais e educadores católicos também utilizaram os impressos e a imprensa periódica como ferramenta para orientar e formar seus leitores. Sgarbi (2001) se refere às "Bibliotecas Pedagógicas Católicas", como um conjunto de títulos ou catálogos de impressos católicos (livros, revistas, jornais, etc.) divulgados pela revista A Ordem e pela Revista Brasileira de Pedagogia, como meios pedagógicos destinados aos intelectuais e ao professorado, respectivamente, no sentido de forjar uma cultura cristã, salvaguardando a amplitude da pedagogia católica que extrapolava o espaço escolar. Os diferentes grupos que travaram disputas pelo controle do aparelho escolar utilizaram largamente o impresso e a imprensa periódica educacional para fazer veicular suas ideias pedagógicas. (CARVALHO, 1994, 2001)

O escolanovismo católico veiculado pelo Boletim Catequético aparece muito imbricado com a arte do "saber fazer" da Pedagogia Moderna. Se no livro A Pedagogia do Catecismo, publicado pelo editor do Boletim, o padre Álvaro Negromonte, há uma série de referências a autores das Ciências da Educação, o mesmo não acontece no periódico. Funcionando mais como uma caixa de utensílios do que um Tratado (CARVALHO, 2006), como é o caso do livro referido destinado ao Curso Normal, tanto os textos veiculados no Boletim quanto aqueles prescritos na Biblioteca da Catequista apresentam como marca distintiva uma pedagogização da doutrina e da moral católica. A circulação de saberes pedagógicos tem, nesse periódico, uma cultura produzida e veiculada "em pílulas" para os professores. ${ }^{15}$ 


\section{Considerações Finais}

As prescrições de leituras para as professoras/catequistas servem como pistas da presença da Igreja nesse movimento de circulação internacional de modelos pedagógicos, considerando a liberdade relativa dos agentes na diversidade dos usos desses modelos, em suas práticas de apropriação e na forma como estas incidem diretamente na construção do mundo social.

Não obstante a aproximação da professora primária com a catequista e os processos de escolarização da catequese terem sido discutidos e trazidos à baila a partir dos Congressos Católicos realizados em Munique, resultando inclusive em um método próprio que foi o indutivo, também conhecido como Método de Munique, a França foi, sobretudo, o grande polo inspirador para o diretor do periódico.

Tenha sido pela dificuldade com o acesso à língua alemã ou mesmo pela facilidade na distribuição de livros franceses no Brasil em relação aos alemães, o método indutivo e as contribuições do Método de Munique chegam ao Brasil pelas lentes dos franceses, sobretudo do abade Quinet e de Marie Fargues. São os seus textos que são traduzidos e indicados, mesmo em língua original, às professoras catequistas do Boletim, mas também às professoras primárias, de modo geral, na Revista do Ensino do Estado de Minas.

Diferentes estratégias foram utilizadas na produção de uma pedagogia moderna no Boletim Catequético. A circulação de modelos internacionais no Boletim pode ser percebida em três instâncias: a recomendações dos autores em seus originais, as traduções e as produções nacionais inspiradas nessas obras. Esta é uma característica que marca os livros prescritos nessa Seção. Todos os livros indicados são livros, potencialmente, de uso escolar. Supondo que a parte pedagógica já havia sido suprida pela Escola Normal, essa seção parece ter como objetivo munir as professoras catequistas de conhecimento acerca da doutrina católica, de livros que mostram como se apropriar da pedagogia nova no ensino religioso, materiais pedagógicos produzidos nessa concepção.

A estratégia de se produzir uma Biblioteca Pedagógica voltada para a formação docente vinha sendo utilizada por diferentes grupos de educadores no Brasil. O escolanovismo católico veiculado pelo Boletim Catequético aparece muito imbricado com a arte do "saber fazer" da Pedagogia Moderna.

\section{Referencias:}

BICCAS, Maurilane de Souza. Impresso pedagógico como objeto e fonte para a História da educação em Minas Gerais (1925-1940). História da educação: ensino e pesquisa.Belo Horizonte: Autêntica, 2006.

BOLETIM CATEQUÉTICO, Belo Horizonte: Editora São José, ano VI, nº 51, junho de 1941, capa.

BOLLIN, Antônio; GASPARINI, Francesco. A catequese na vida da Igreja: notas de história. São Paulo: Paulinas, 1998.

BOURDIEU, Pierre. Gênese e Estrutura do Campo Religioso. BOURDIEU, Pierre. A Economia das Trocas Simbólicas. Org. Sérgio Miceli. São Paulo. Ed. Perspectiva, 2004.

BOURDIEU, Pierre. Campo do Poder, Campo Intelectual e Habitus de Classe. 
BOURDIEU, Pierre. A economia das trocas simbólicas. São Paulo: Perspectiva, 2005. p. 183-202.

CARVALHO, Marta Maria Chagas de. A caixa de utensílios, o tratado e a biblioteca: pedagogia e práticas de leitura de professores. VIDAL, Diana Gonçalves; HILSDORF, Maria Lúcia (org.). Tópicas de História da Educação. São Paulo: EDUSP, 2001. p. 137167.

CARVALHO, Marta Maria Chagas de. A Escola Nova e o impresso: um estudo sobre estratégias editoriais de difusão do escolanovismo no Brasil. FARIA Filho, Luciano Mendes. Modos de ler, formas de escrever: estudos de História da Leitura e da Escrita no Brasil. Belo Horizonte: Autêntica, 2001. p. 66-86.

CARVALHO, Marta Maria Chagas de. Livros e revistas para professores: configuração material do impresso e circulação internacional de modelos pedagógicos. PINTASSILGO, Joaquim et all. (org.). História da escola em Portugal e no Brasil: circulação e apropriação de modelos culturais. Lisboa: Colibri, 2006.

CARVALHO, Marta Maria Chagas de. Uso do Impresso nas Estratégias Católicas de Conformação do campo doutrinário da Pedagogia (1931-1935). In: Cadernos Anped, n. 7, 1994. p. 41-60.

CERTEAU, Michel de. A invenção do cotidiano: artes de fazer. Petrópolis/RJ: Editora Vozes, 1994.

CHARTIER, Roger. A História Cultural: entre práticas e representações. Rio de Janeiro: Bertrand Brasil, 1990.

CRISTINO, Horácio C. (Dom). O Catecismo na História da Igreja. Boletim de Pastoral Litúrgica. Lisboa: Secretariado Nacional de Liturgia, ano XIX, julho-setembro de 1994, p. 102-119.

FARGUES, Marie. Les Méthodes actives dans l'Enseignement religieux. France/Belgique: Les Éditions du Cerf, Juvisi (Seine-et-Oise), 1934. (Collection Les Sciences et l'Art de l'Éducation).

LUSTOSA, Oscar. Catequese Católica no Brasil: para uma história da evangelização. São Paulo: Edições Paulinas, 1992. (Coleção Estudos e Debates Latino-Americanos).

MONTEIRO, Judith. Catequista. Boletim Catequético, Belo Horizonte: Editora São José, ano VI, no 51, junho de 1941, p. 13.

MUNAKATA, Kazumi. Produzindo livros didáticos e paradidáticos. São Paulo: PUC, 1997. (Tese de Doutoramento).

ORLANDO, Evelyn de Almeida. Por uma civilização cristã: a coleção Álvaro Negromonte e a pedagogia do catecismo. Dissertação (Mestrado em Educação) São Cristóvão/SE: Universidade Federal de Sergipe, 2008. 
ORLANDO, Evelyn de Almeida. A Igreja Católica e a pedagogização da sociedade: um projeto civilizatório orientado à família e à escola via impressos. Tese (Doutorado em Educação), Rio de Janeiro: Universidade do Estado do Rio de Janeiro, 2013.

PIO XI. Texto de Apresentação. Boletim Catequético, Belo Horizonte: Editora São José, ano VI, $n^{\circ} 51$, junho de 1941, capa.

PRADEL, Henri. Alguns traços para a educadora perfeita. Boletim Catequético, Belo Horizonte: Editora São José, ano IV, no 35, p. 12, agosto de 1939.

SGARBI, Antônio Donizetti. Bibliotecas Pedagógicas Católicas: estratégias para construir uma civilização cristã e conformar o campo pedagógico através do impresso (1929-1938). Tese (Doutorado em Educação). São Paulo: Pontifícia Universidade Católica, 2001.

TOLEDO, Maria Rita de Almeida. Coleção Atualidades Pedagógicas: do projeto político ao editorial (1931-1981). São Paulo: Pontifica Universidade Católica, 2001. (Tese de doutoramento).

VIDAL, Diana Gonçalves. O exercício disciplinado do olhar: livros, leituras e práticas de formação docente no Instituto de Educação do Distrito Federal (1932-1937). Bragança Paulista, Editora da Universidade São Francisco, 2001.

\section{Fontes Documentais}

BOLETIM CATEQUÉTICO. Belo Horizonte: Editora São José, nº 1 - 38, Ano I - IV, $1936-1939$.

BOLETIM CATEQUÉTiCO. Belo Horizonte: Editora São José, no 49 - 52, Ano VI, 1941.

\footnotetext{
${ }^{15}$ Este trabalho é parte de uma pesquisa maior desenvolvida com apoio da FAPERJ - Fundação de Amparo à Pesquisa do Estado do Rio de Janeiro.
} 
${ }^{15}$ Professora do Programa de Pós-Graduação em Educação e do Curso de Pedagogia da Pontifícia Universidade Católica do Paraná. Doutora em Educação pela Universidade do Estado do Rio de Janeiro. Email: evelynorlando@gmail.com

${ }^{15}$ O Boletim Catequético foi um periódico publicado em Belo Horizonte, em 1936, sob a direção do padre Álvaro Negromonte e pode ser lido no conjunto de sua Biblioteca Pedagógica. Sobre esse tema, ver Orlando (2013).

15 'Na 'Realschule' de Hecker, Felbiger aprende o que aplica a todas as matérias, também ao catecismo e à história sagrada. Pode-se sintetizar em: método do ensino primário, ensino simultâneo, leitura e memorização, uso de tabelas e esquemas gerais e particulares, ensino por meio de perguntas e respostas". (PRAIDO apud BOLLIN \& GASPARIN, 1998, p. 155)

${ }^{15} \mathrm{O}$ conceito de campo é entendido neste trabalho na perspectiva de Bourdieu (2004). O conceito de campo é utilizado aqui na perspectiva proposta por Pierre Bourdieu e diz respeito ao universo no qual estão inseridos os agentes e as instituições que produzem, reproduzem ou difundem um conhecimento específico. O campo é um mundo social que possui uma certa autonomia e que se configura como campo de forças e de lutas, no qual essas relações de forças alimentam a conservação transformação desse próprio campo e o mantém autônomo em relação às pressões externas do mundo que o envolve.( BOURDIEU, 2004, p. 20-29).

${ }^{15}$ Os estudos sobre o método de Munique, no Brasil, ainda são escassos assim como a sua influência na pedagogia católica brasileira, conseqüência direta da pouca atenção que o catolicismo vem recebendo dos estudos da área, sobretudo no que tange às práticas pedagógicas modernizadoras da Igreja. O método de Munique ressaltou a necessidade de se atentar para a criança, através das contribuições da Psicologia, e manteve uma relação muito próxima com a pedagogia Herbartiana, conforme lembra Passos (1998). A tese de doutoramento de Mauro Passos (1998) destaca o movimento catequético de Munique, ocorrido no início do século XX, ao tratar da influência da pedagogia herbartiana para a catequese, e aponta para a repercussão que teve, no Brasil, na década de 30, com Negromonte e Waleska Paixão. (ORLANDO, 2008)

${ }^{15}$ Inspetor do Ensino Religioso da Diocese de Paris, o abade Quinet foi um dos autores mais citados pelos católicos envolvidos com a modernização do ensino de catecismo no Brasil. Seu livro Apontamentos do Catequista (vol. 1),teve tradução autorizada por Waleska Paixão e foi publicado no Brasil em 1935.

${ }^{15}$ Marie Fargues era uma das principais referências na pedagogia catequística francesa e seus textos foram largamente utilizados na Revista do Ensino, periódico publicado pelo Governo de Minas para as professoras da Instrução Pública, e no Boletim Catequético. Seus livros, traduzidos ou não, constavam em todas as prescrições de leitura para as catequistas.

${ }^{15}$ Os livros referenciados eram todos vendidos pelo Boletim aos professores, mediante pedidos e remessa do valor dos mesmos acrescido das despesas postais. Já as revistas internacionais nunca foram recomendadas, possivelmente pelo alto custo e, talvez pelo fato de o Boletim Catequético sintetizar as contribuições de diversas dessas publicações.

${ }^{15}$ L. Dechamps era professor de Pedagogia da Universidade de Louvain e diretor da Escola Normal de Braine-le-Comte.

${ }^{15}$ Franz De Hovre era abade e professor de Pedagogia de Anvers e de Gand, considerado um expoente da Pedagogia Católica. Seus livros Pedagogos e Pedagogia do Catolicismo e Ensaios de Filosofia Pedagógica foram obras referências e citadas, frequentemente, no campo católico.

${ }^{15}$ A Coleção Les Sciences et l'Art de l'Éducation era dirigida por um grupo de especialistas da França e da Bélgica e se propunha a esclarecer os professores acerca do movimento pedagógico contemporâneo, analisar o ponto de vista científico à luz da doutrina católica e extrair, assim, em vista de uma verdadeira preparação da criança para a vida, os resultados adquiridos das Ciência da Educação (traduzido pela pesquisadora do livro Les Méthodes actives dans l'Enseignement religieux (FARGUES, 1934).

${ }^{15}$ O termo "uso" aqui é usado propositalmente para indicar uma relação que estabelece entre leitor e livros escolar que foge das tradicionais práticas de leitura. Tal perspectiva, indicada por Chartier (1990), em relação ao livro e os leitores de modo geral, sinalizando para as diversidade de práticas de leitura foi apropriada por Munakata (1997) e discutida no âmbito dos livros didáticos e paradidáticos. Faço, neste artigo, apoiada nesses dois autores, movimento semelhante em relação ao livro escolar.

${ }^{15}$ Conforme Carvalho (2001) entre os "usos prescritos" e os "usos efetivos" há um hiato de difícil apreensão e que se constitui, portanto, em um campo de investigação a ser aprofundado nas pesquisas históricoeducacionais.

${ }^{15}$ Expressão toma de empréstimo de Toledo (2001). 